\title{
Differential Expression of Adhesion Molecules within the Human Thymus
}

\author{
JULIE NAIMA REZA* and MARY A. RITTER \\ Department of Immunology, Royal Postgraduate Medical School, Du Cane Road, London W12 ONN, U.K.
}

\begin{abstract}
Development of a diverse, MHC-restricted yet self-tolerant T-cell repertoire occurs within the thymus, and requires contact between developing $\mathrm{T}$ cells and their stromal microenvironment. Such interactions are likely to depend on the combinatorial effect of specific adhesion molecules. As a preliminary step to determining their role in T-cell development, we have studied the distribution of LFA-1/ICAM-1, CD2/LFA-3, VLA-4/VCAM-1, and HECA 452-antigen/E-Selectin ligand pairs on frozen sections of human thymus. Using two color-immunohistochemistry, and a variety of cell-lineage markers that reveal the nature of the cells on which these adhesion molecules are located, we find a differential distribution of adhesion molecules, with some being shared by both endothelial and epithelial cells. We also identify the VCAM-1-positive subpopulation as cortical macrophages. The relevance of these findings to thymopoiesis is discussed.
\end{abstract}

KEYWORDS: Adhesion molecules, macrophages, stromal cells, thymus.

\section{INTRODUCTION}

A fully functional immune system requires the generation of a diverse $\mathrm{T}$-cell repertoire, which is both major histocompatibility-(MHC) restricted and self-tolerant. This development occurs in the thymus (reviewed by Boyd and Hugo, 1991; Ritter and Crispe, 1992; Boyd et al., 1993; and Ritter and Boyd, 1993), where bone marrow-derived pluripotent stem cells first enter the thymus and subsequently interact with stromal cells. The developing thymocytes change phenotypes and also undergo positive and negative selection, rendering them self-MHCrestricted (Sprent et al., 1975; Jenkinson et al., 1985; Kappler et al., 1987; Marrack et al., 1988) and self-tolerant (Lo and Sprent, 1986; Marrack et al., 1988; Berg et al., 1989), respectively. Thus, interactions between thymocytes and stromal cells, whether cell-cell or via soluble molecules, must provide signals for the migration, proliferation, maturation, and selection of T cells, as well as signals for maintaining the structural integrity of the thymic microenvironment. Details about such interactions are unclear, but it is likely that adhesion molecules are involved.

\footnotetext{
${ }^{*}$ Corresponding author.
}

Adhesion molecules can be divided into several groups (reviewed by Albelda and Buck, 1990; Springer, 1990; and Pigott and Power, 1993): (a) the Immunoglobulin superfamily (e.g., CD2, Vascular Cell Adhesion Molecule [VCAM]-1, Intercellular Cell Adhesion Molecule [ICAM]-1, and Leucocyte Function Related Antigen [LFA]-3), which are involved in cell-cell adhesion; (b) Integrins (e.g., Very Late Antigen [VLA]-4 and LFA-1) involved in cell-cell and cell-substratum adhesion; (c) Selectins/LEC-CAMS (cell adhesion molecules with several lectin-like domains) (e.g., Endothelial-Selectin [E-Selectin]) that mediate interaction of leucocytes with endothelial cells; (d) Cadherins, involved in homophilic cell-cell adhesion; and (e) homing receptors that target lymphocytes to specific lymphoid tissues. Other molecules, such as carbohydrate moieties of glycoproteins (e.g., sialyl Lewis X [sLeX] related structures) or constituents of the extracellular matrix (e.g., fibronectin [FN]) may also be involved in adhesion.

In the periphery, different functions and distributions can be attributed to various (endothelial) adhesion molecules, (reviewed by Shimizu et al., 1992), and it is likely that such diversity is also found in the thymus. Two major cell lineages that thymocytes encounter within the thymus are the endothelium (described as the "gatekeeper" regulating lympho- 
cyte interactions with tissue) and the epithelium. Therefore, in this paper, by concentrating on adhesion molecules found on peripheral endothelium or epithelium (see Table 1), whose ligands may be found on $\mathrm{T}$ cells, we attempt to elucidate the role of adhesion molecules during $\mathrm{T}$-cell development within the thymus. Using immunohistochemical techniques on cryostat sections, we studied the expression of the receptor-ligand pairs LFA-1/ ICAM-1 or ICAM-2; CD2/LFA-3; VLA-4/VCAM-1 or fibronectin; and the antigen recognized by HECA 452 (HECA 452-Ag)/E-Selectin on human pediatric thymus. We report a differential distribution of adhesion molecules on stromal cells (epithelium, endothelium, and macrophages) within the thymus, and identify the VCAM-1 positive cell subpopulation as cortical macrophages.

\section{RESULTS}

Single immunoperoxidase staining of various adhesion molecules and their ligands on frozen human thymus sections can be seen in Figs. 1-3. Results of double immunoenzyme staining versus "lineagespecific" markers are summarized in Table 2 and double staining of VCAM-1 versus "lineagespecific" markers can be seen in Fig. 4 .

\section{LFA-1, ICAM-1, and ICAM-2}

The anti-LFA-1 antibody used (Table 3) recognizes CD11a, the alpha chain of LFA-1. Our results show that this antibody stains thymocytes throughout the cortex and medulla, with medullary thymocytes staining more strongly (Figs. 1a and 1e). Epithelial cells appear LFA-1-negative (however, when lymphocyte staining is strong, it is difficult to exclude very low levels of staining on nonlymphoid cells). Anti-ICAM-1, on the other hand, reveals a predominantly medullary, nonlymphoid pattern of staining (Figs. 1b and 1f). Double staining experiments show that ICAM-1 can be found at relatively high levels on a subpopulation of medullary and cortical epithelial cells, some macrophages, as well as blood vessels. The two different anti-ICAM-1 antibodies used, 6.5B5 (not shown) and 8.486, gave similar staining patterns, although 8.486 showed stronger staining, especially of epithelial cells (Fig. 1c). This difference may be attributable to a difference in affinity of the antibodies. ICAM-2 was found to be negative in the thymus (Fig. 1d).

\section{CD2 and LFA-3}

Anti-CD2 stains thymocytes, with epithelial and endothelial cells being CD2-negative (Fig. 2a). The

TABLE 1

Characteristics and Peripheral Distribution of the Adhesion Molecules Studied

\begin{tabular}{|c|c|c|c|c|c|c|c|}
\hline T-cell molecule & $\operatorname{Mwt}(k D)$ & Family & $\begin{array}{l}\text { Distribution } \\
\text { (peripheral) }\end{array}$ & Counterreceptor & Mwt (kD) & Family & $\begin{array}{l}\text { Distribution } \\
\text { (peripheral) }\end{array}$ \\
\hline \multirow[t]{2}{*}{$\begin{array}{l}\text { LFA-1 }\left(\alpha_{\mathrm{L}} \beta_{2} ;\right. \\
\text { CD11a/CD18) }\end{array}$} & $180 / 95$ & INT & $\begin{array}{l}\text { Lymphocytes, } \\
\text { neutrophils, } \\
\text { myelomonocytes }\end{array}$ & ICAM-1 (CD54) & $76-114$ & IG & $\begin{array}{l}\text { Activated } \\
\text { leucocytes, } \\
\text { endothelium, } \\
\text { epithelial cells, } \\
\text { fibroblasts. }\end{array}$ \\
\hline & & & & $\begin{array}{l}\text { ICAM-2 } \\
\text { (CD102) }\end{array}$ & $55-60$ & IG & $\begin{array}{l}\text { Constitively } \\
\text { expressed on } \\
\text { leucocytes and } \\
\text { endothelium }\end{array}$ \\
\hline $\begin{array}{l}\text { CD2 (LFA-2; T11; } \\
\text { Tp50, Leu 5) }\end{array}$ & $47-58$ & IG & $\mathrm{T}$ cells NK cells & LFA-3 (CD58) & $50-77$ & INT & $\begin{array}{l}\text { Various cell } \\
\text { types }\end{array}$ \\
\hline \multirow[t]{2}{*}{$\begin{array}{l}\text { VLA-4 }\left(\alpha_{4} \beta_{1} ;\right. \\
\text { CD } 49 \text { d/CD29; } \\
\text { LPAM-2 [mouse]) }\end{array}$} & $160 / 130$ & INT & $\begin{array}{l}\text { Resting lympho- } \\
\text { cytes, mono- } \\
\text { cytes, melanoma } \\
\text { cells }\end{array}$ & $\begin{array}{l}\text { VCAM-1 } \\
\text { (INCAM110; } \\
\text { CD106) }\end{array}$ & $\begin{array}{l}90 \\
-\end{array}$ & IG & $\begin{array}{l}\text { Activated } \\
\text { endothelium }\end{array}$ \\
\hline & & & & Fibronectin & & & $\begin{array}{l}\text { Extracellular } \\
\text { matrix }\end{array}$ \\
\hline $\begin{array}{l}\text { HECA } 452 \mathrm{Ag} \\
\text { (sLeX-related an- } \\
\text { tigens) }\end{array}$ & & $\mathrm{CHO}$ & $\begin{array}{l}\text { Some T cells and } \\
\text { myelomonocytic } \\
\text { cells }\end{array}$ & $\begin{array}{l}\text { E-Selectin } \\
\text { (ELAM-1; } \\
\text { LECAM-2; } \\
\text { CD62E) }\end{array}$ & 115 & SEL & $\begin{array}{l}\text { Activated } \\
\text { endothelium }\end{array}$ \\
\hline
\end{tabular}

Abbreviations: $\mathrm{Mwt}=$ Molecular weight; $\mathrm{INT}=$ integrin; $\mathrm{IG}=$ immunoglobulin; $\mathrm{CHO}=$ carbohydrate; and SEL $=$ selectin . 

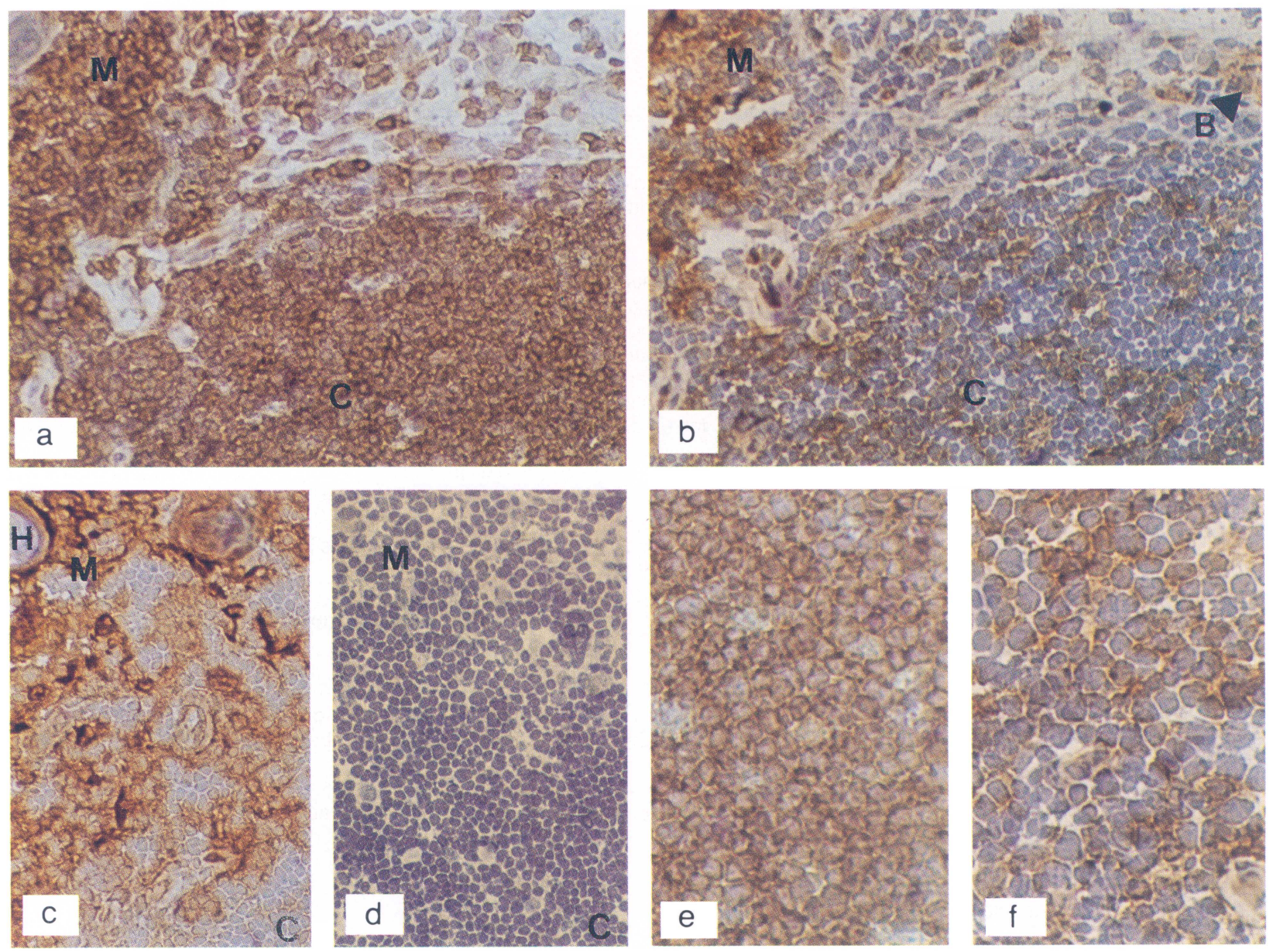

FIGURE 1 Immunoperoxidase staining on human thymus sections. Sections were incubated with anti-LFA-1, anti-ICAM-1, or anti-ICAM-2, followed by peroxidase conjugated secondary antibody, development of reaction with DAB substrate, and haematoxylin counterstain. (a) Staining pattern obtained with anti-LFA-1 showing staining of thymocytes throughout the cortex (C) and medulla (M), with medullary thymocytes staining more strongly. Epithelial cells are LFA-1 negative $(x 360)$. (b) Staining pattern obtained with anti-ICAM-1 (6.5B5) showing ICAM-1 on cortical and medullary epithelium and on some macrophages ( $x$ 360). (c) Staining pattern obtained with anti-ICAM-1 (8.486) showing strong labeling of medullary epithelium $(\times 360)$. (d) Staining pattern obtained with anti-ICAM-2 showing ICAM-2 is not expressed at levels detected by this technique in human thymus (x 360). (e and f) Staining pattern obtained with anti-LFA-1 and anti-ICAM-1 (6.5B5), respectively, under higher magnification. The difference in thymocyte versus epithelial staining is clearly visible $(x 720)$. Figures $(a)$ and $(b)$ are from serial sections. $B=$ blood vessel; $H=H a s s a l l ' s$ corpuscle; $\mathrm{C}=$ cortex; and $\mathrm{M}=$ medulla. See Colour Plate I.

ligand for CD2 (LFA-3) is on cortical and medullary epithelium, macrophages, and blood vessels (Fig. 2b and Table 2). Thymocytes also appear weakly positive.

\section{HECA 452-Ag (sLeX-Related antigens) and E- Selectin}

HECA 452 stains blood vessels (Fig. 2c)-especially those at the corticomedullary junction, although it can also be found weakly staining blood vessels in septa/trabeculae. This staining of thymus with
HECA 452 is contrary to the lack of thymic staining reported by Duijvestijn et al., (1988). Possibly this difference can be attributed to a difference in the method of tissue preparation. E-Selectin stains some extrathymic blood vessels, and weakly stains some blood vessels in the corticomedullary junction (Fig. 2d).

\section{VLA-4, VCAM-1, and Fibronectin}

VLA-4 is expressed on medullary, and more strongly on cortical thymocytes (comparable to the 
TABLE 2

Lineages of Cells Expressing Various Adhesion Molecules as Determined by Double Immunoenzyme Labeling of Human Pediatric Thymus Sections

\begin{tabular}{|c|c|c|c|c|c|}
\hline Cell subpopulation & ICAM-1 & ICAM-2 & LFA-3 & E-Selectin & VCAM-1 \\
\hline Cortical epithelium & $++\mathrm{sp}$ & - & ++ & - & $(+)$ \\
\hline Medullary epithelium & $+++\mathrm{sp}$ & - & ++ & - & $(+)$ \\
\hline Medullary blood vessels & + & - & + & - & $(+) /-$ \\
\hline Blood vessels in C-M junction & $(+)$ & - & ++ & $(+)$ & $(+) /-$ \\
\hline Cortical blood vessels & $(+)$ & - & ++ & - & $(+) /-$ \\
\hline Blood vessels in septae & + & - & + & + & $(+) /-$ \\
\hline Medullary macrophages & $(+) \mathrm{sp}$ & - & $(+) \mathrm{sp}$ & - & - \\
\hline Cortical macrophages & $(+) \mathrm{sp}$ & - & $(+) \mathrm{sp}$ & - & +++ \\
\hline Medullary lymphocytes ${ }^{a}$ & - & - & $(+) /+$ & - & - \\
\hline Cortical lymphocytes ${ }^{a}$ & - & - & $(+) /+$ & - & - \\
\hline
\end{tabular}

TABLE 3

Anti-adhesion Molecule Antibodies Used

\begin{tabular}{lll}
\hline Antibody & Isotype/species & Clone/name \\
Anti-LFA-1 $^{\mathrm{a}}$ & IgG1/mouse & MHM-24 \\
Anti-ICAM-1 $^{\mathrm{b}}$ & IgG1/mouse & $6.5 \mathrm{~B} 5$ \\
& IgG1/mouse & 8.486 \\
Anti-ICAM-2 $^{\mathrm{c}}$ & $--/$ rabbit & $2 \mathrm{RAP}$ \\
Anti-CD2 $^{\mathrm{a}}$ & IgG1/mouse & T9-10 \\
Anti-LFA-3 $^{\mathrm{d}}$ & IgG1/mouse & TS2/9.1.4.3 \\
HECA 452 $^{\mathrm{b}}$ & IgM/rat & HECA 452 \\
Anti-E-Selectin $^{\mathrm{b}}$ & IgG1/mouse & $1.2 \mathrm{~B} 6$ \\
Anti-VLA-4 $^{\mathrm{b}}$ & IgG1/mouse & HP2/1 \\
Anti-VCAM-1 $^{\mathrm{b}}$ & IgG1/mouse & $1 \mathrm{G} 11$ \\
& IgG1/mouse & $1 \mathrm{E5}$ \\
& IgG1/mouse & $6 \mathrm{D} 9$ \\
& IgG1/mouse & $3 \mathrm{~B} 10$ \\
& IgG1/mouse & $1.4 \mathrm{C} 3$ \\
Anti-fibronectin $^{\mathrm{a}}$ & $--/$ rabbit & A245 \\
\hline
\end{tabular}

Antibodies were obtained either as monoclonal preparations or as polysera. ${ }^{a}$ Dako, High Wycombe, U.K. ${ }^{b}$ Generous gifts of D. Haskard, R.P.M.S., London, U.K

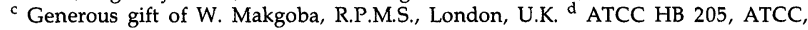
Rockville, Maryland 'Serotec, Oxford, U.K.

results obtained by Watt et al., 1992). It does not appear to be expressed on other cell lineages (Fig. 3a)-a pattern completely different to that given by two of its ligands, VCAM- 1 and FN (Figs. $3 b$ and 3c, respectively). Several different anti-VCAM-1 antibodies were used $(1 \mathrm{G} 11,1 \mathrm{E} 5,6 \mathrm{D} 9,3 \mathrm{~B} 10$, and $1.4 \mathrm{C} 3)$, some of which recognize nonoverlapping epitopes. These all gave a similar staining pattern, strongly staining "patches" in the cortex (e.g. Fig. 3d showing staining obtained with 3B10), whilst weakly staining some epithelial and endothelial cells. Double immunoenzyme staining of anti-VCAM-1 (1G11) versus anti-macrophage (anti-CD68) reveal these "patches" as cortical macrophages (Fig. 4a). Medullary macrophages are VCAM-1-negative (Fig. $4 \mathrm{~b})$. Double immunoenzyme staining of antiVCAM-1 (1G11) versus anti-laminin (used as a marker for blood vessels and basement membrane) shows that VCAM-1-positive cells often appear closely associated with blood vessels (Fig. 4c).

\section{DISCUSSION}

T-cell development occurs under the influence of stromal elements in the thymus, and probably involves adhesion molecules. Little is known about the role of such molecules within the thymus, (reviewed by Patel and Haynes, 1993), although a degree of circumstantial evidence supports their involvement in thymopoiesis.

In many cases, adhesion molecule expression or binding affinity can be increased following cytokine stimulation or cell activation. Further, one adhesion "receptor" may have multiple ligands, or multiple adhesion receptors may exist for one particular ligand. Such potential for upregulation of avidity and expression, the existence of multiple adhesion pathways, and the expression of different adhesion molecules leading to different intracellular events (as suggested by Albelda and Buck, 1990) provide a variety of ways in which cells may interact with one another to give a range of results, and is likely to be of importance in lymphocyte-stromal interactions in the thymus.

In this paper, we have studied the expression of various adhesion molecules on stromal cells, and compared expression to that of their ligands in situ using immunohistochemical techniques. It should be noted that some antigens lose their antigenicity during tissue preparation or may be present at levels too low to be detected by the techniques used in this paper, yet may still be of biological significance.

\section{LFA-1, ICAM-1, and ICAM-2}

Our studies show that LFA-1 appears to be expressed on all thymocytes, and at slightly higherlevels in the medulla. This would agree with experiments where LFA-1 is expressed on memory 

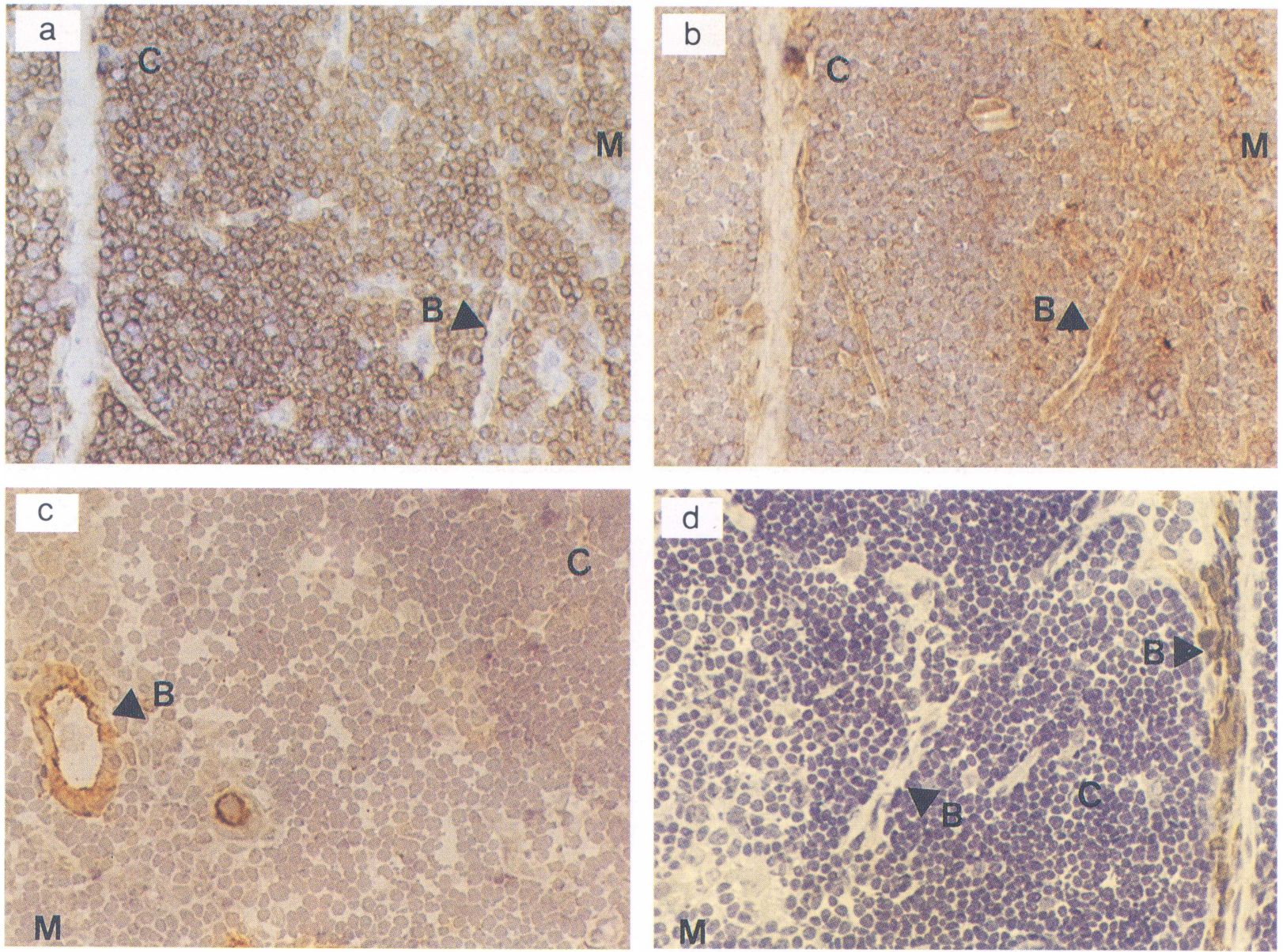

FIGURE 2 Immunoperoxidase staining on human thymus sections. Sections were incubated with anti-CD2, anti-LFA-3, HECA-452, and anti-E-Selectin, followed by peroxidase conjugated secondary antibody, development of reaction with DAB substrate, and haematoxylin counterstain. (a) Staining pattern obtained with anti-CD2, showing CD2 is distributed on all thymocytes. Epithelial and endothelial cells are CD2-negative (x 360). (b) Staining pattern obtained with anti-LFA-3, showing LFA-3 is on cortical and medullary epithelium, some macrophages, and also on blood vessels (B). Weak staining of thymocytes can also be seen (x 360). (c) Staining pattern obtained with HECA 452, showing staining of high-endothelial-like blood vessels (x 360). (d) Staining pattern obtained with anti-E-Selectin, showing staining of extrathymic blood vessels but very little/no staining of cortical blood vessels $(x 360)$. $B=$ blood vessels; $C$ = cortex; and $M=$ medulla. See Colour Plate II.

$\mathrm{T}$ cells at higher levels than naive $\mathrm{T}$ cells (Poggi and Zocchi, 1992)-medullary thymocytes are likely to have undergone selective events, and thus, in a manner of speaking, have "seen" antigen. Thus, an increase in LFA-1 expression would seem to be a result of development rather than a mechanism involved in the developmental process itself, contradicting studies by Fine and Kruisbeek (1991) and Carlow et al., (1992) that indicated that LFA-1 may be important in T-cell development/education.

LFA-1 recognizes ICAM-1, ICAM-2, ICAM-3, and ICAM-R (Marlin and Springer, 1987; Staunton et al., 1989; de Fougerolles et al., 1991; de Fougerolles and Springer, 1992; Vaseux et al., 1992). In our experiments, we find that ICAM-1 is expressed at low levels on thymic blood vessels, suggesting that endothelial ICAM-1 has no particular relevance to thymic progenitor recruitment, whereas it is expressed at high levels on all epithelium, and thus may be important in all stages of thymocyte development. The absence of thymic ICAM-2 in our studies (also noted by de Fougerolles et al., 1991) implies that this ligand for LFA-1 is not involved in thymic T-cell development. 

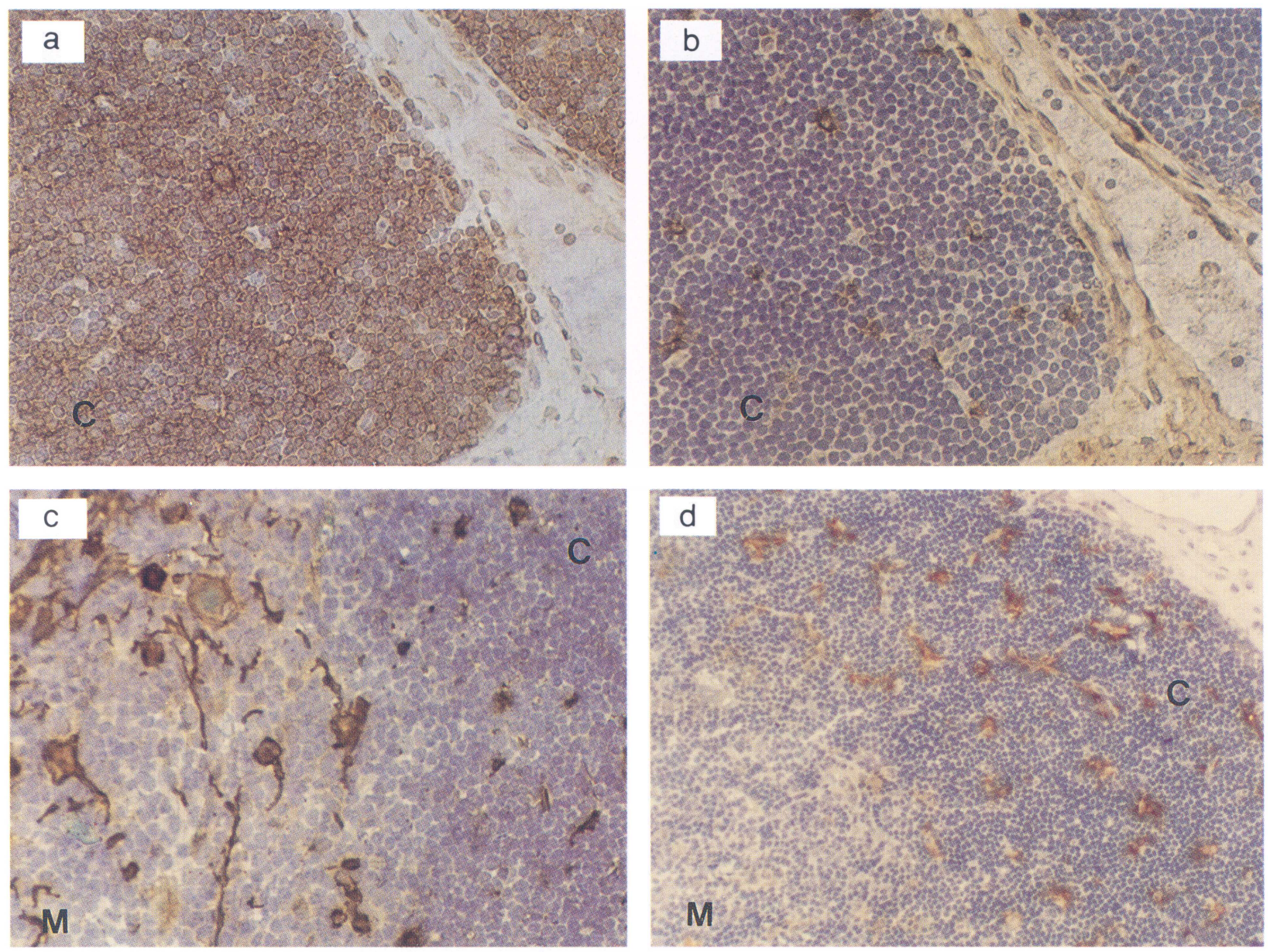

FIGURE 3 Immunoperoxidase staining on human thymus sections. Sections were incubuted with anti-VLA-4, anti-VCAM-1, and anti-FN, followed by peroxidase conjugated secondary antibody, development of reaction with DAB substrate, and haematoxylin counterstain. (a) Staining pattern obtained with anti-VLA-4, showing staining of all thymocytes (x 360). (b) Staining pattern obtained with anti-VCAM-1 (1G11), showing "patches" of staining in the cortex (C) and weak staining of septae (x 360). (c) Staining pattern obtained with anti-FN, showing staining of extracellular matrix (x 360). (d) Typical staining pattern obtained with anti-VCAM-1 antibody (3B10), showing staining of cortical macrophages (x 180). Figures (a) and (b) are from serial sections. B = blood vessels; C = cortex; and $\mathrm{M}=$ medulla. See Colour Plate III.

\section{CD2 and LFA-3}

LFA-3 is a ligand for CD2. (More recently, it has been suggested that CD48 may exist as an alternative ligand for CD2 [Arulanandam et al., 1993], although it may have limited, if any, functional significance.) Our results show that CD2 is distributed evenly on all thymocytes, whereas LFA-3 stains cortical and medullary epithelium and weakly stains macrophages. In flow cytometric studies (Watt et al., 1992), thymocytes appeared LFA-3negative-however, this study indicates that some thymocytes may express low levels of LFA-3. The presence of CD2 on most thymocytes probably indicates it has different functions in different re- gions. To date, its importance in T-cell development has mainly been by implication-for instance, antiCD2 monoclonal antibodies can perturb the interaction of thymocytes with LFA-3-positive thymic epithelium (Denning et al., 1987). However, murine thymic organ cultures in the presence of anti-CD2 monoclonal antibodies (Kyewski et al., 1989) and homozygous CD2 mutant mice (Killeen et al., 1992) develop normal $\mathrm{T}$ cells, implying that $\mathrm{CD} 2$ is dispensable for the development and function of murine T cells. Further, Zocchi et al. (1990) have found that CD2 is absent from immature human thymocytes that express both CD3 and CD28. Thus, the role of CD2/LFA-3 interactions in the development 

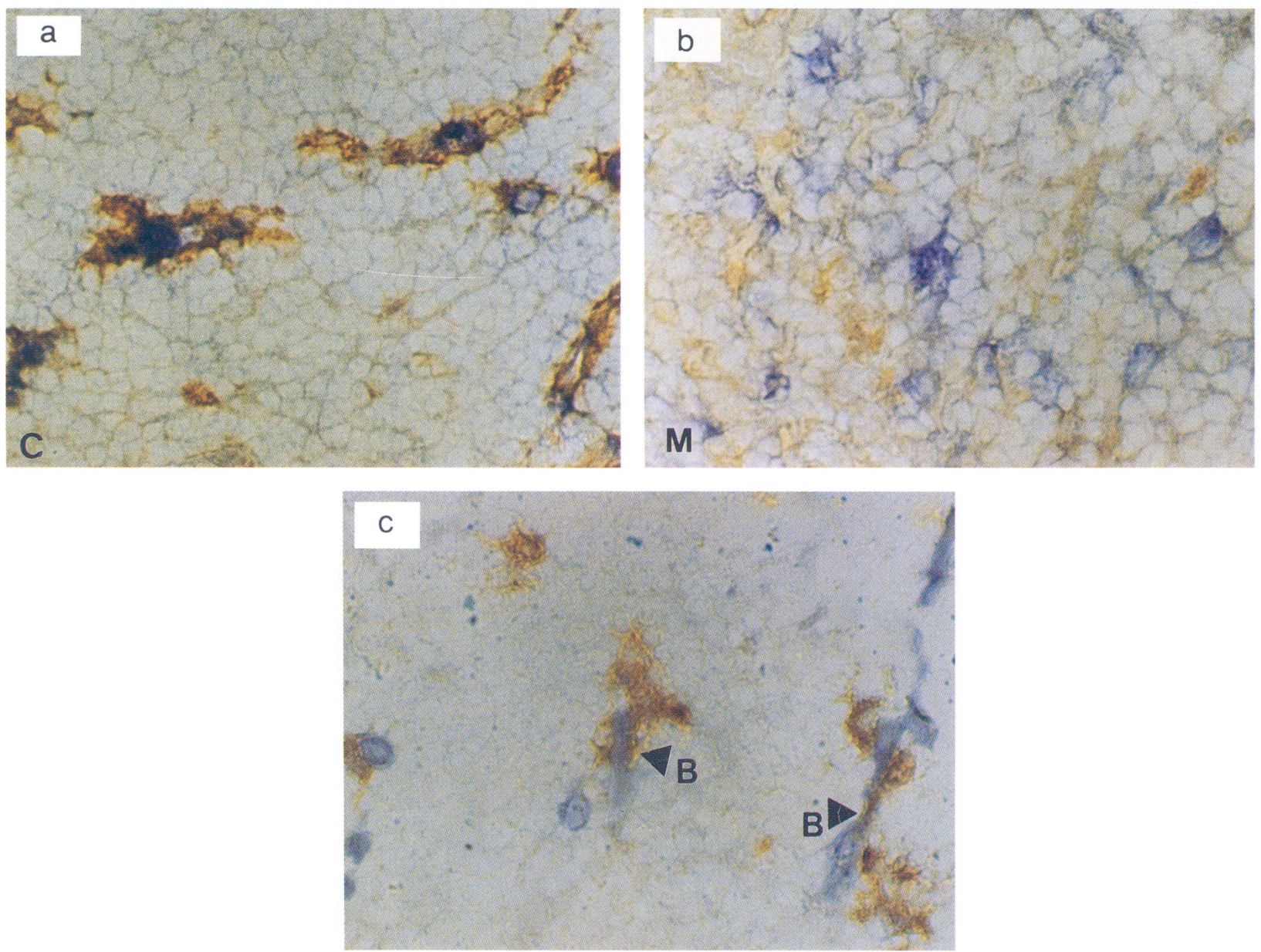

FIGURE 4 ( $a$ and $b)$ Double immunoenzyme labeling of human thymus sections (anti-VCAM-1 versus anti-macrophage). Sections were incubated with anti-VCAM-1 (1G11), stained by the immunoperoxidase method (brown), followed by anti-macrophage (anti-CD68) antibody, stained by the immunoalkaline phosphatase method (blue). Sections were not counterstained. Anti-VCAM-1 can be seen to strongly stain cortical macrophages, but not medullary macrophages $(x 720)$. (c) Double immunoenzyme labeling of human thymus sections (anti-VCAM-1 versus anti-laminin). Sections were incubated with anti-VCAM-1 (1G11), followed by the immunoperoxidase method (brown), and then incubated with anti-laminin (to act as a marker for basement membrane associated with blood vessels and capsule) followed by the immunoalkaline phosphatase method (blue). Sections were not counterstained. VCAM-1-positive cells can be seen to be associated with cortical blood vessels ( $x 720)$. $B=$ blood vessels; $C=$ cortex; and $M=$ medulla. See Colour Plate IV.

of $\mathrm{T}$ cells in humans remains speculative, although our results do not preclude such an involvement.

\section{HECA 452-Ag (sLeX-Related Antigens) and E-Selectin (ELAM-1)}

HECA 452 is a rat monoclonal antibody that detects a human endothelial cell-differentiation antigen selectively expressed on high endothelium -it intensely stains all high endothelial venules within lymphoid organs, but not nonlymphoid tissues (Duijvestijn et al., 1988). The HECA 452-Antigen (HECA 452-Ag) is also called the Cutaneous
Lymphocyte-associated Antigen (CLA), found on some $\mathrm{T}$ cells and myelomonocytic cells, as well as endothelial cells. These CLA/HECA 452-Ag + cells bind selectively to E-Selectin. HECA 452 blocks binding of $\mathrm{T}$ lymphocytes to E-Selectin transfectants, and binding of HECA 452 or E-Selectin to lymphocytes is abrogated by neuraminidase, suggesting that HECA 452-Ag/CLA may be a modified form of sialyl-Lewis $X$ (sLeX) found on neutrophils (Berg et al., 1991), and that the HECA 452-Ag is the ligand for E-Selectin.

Our studies showed that E-Selectin expression is found on blood vessels in septae, and to a lesser 
extent on corticomedullary blood vessels, suggesting that it is important in leucocyte traffic. It was noted that neutrophils were commonly found near these E-Selectin positive cells, implying that E-Selectin may be involved in neutrophil recruitment. In the thymus, it is possible that leucocytes produce IL-1 (known to increase E-Selectin synthesis in peripheral endothelium), and thus increase leucocyte interaction with thymic endothelium. E-Selectin may function in initiating leucocyte-endothelium cell adhesion, and hence it may be important in recruitment of $\mathrm{T}$-cell precursors to various thymic subcompartments. If this was the case, one would expect the ligand for E-Selectin to be found on leucocytes/thymocytes. However, in our experiments, expression of the "assumed" ligand (HECA $452-\mathrm{Ag}$ ) seems to be localized mainly to blood vessels in the corticomedullary junction, although some staining can be seen on extrathymic blood vessels, neutrophils, and on cells in the medulla. These latter were not identified in these experiments, but two color flow cytometry will indicate if some are T-cell precursors, although Picker et al. (1990) have found that $99 \%$ of thymocytes are HECA 452-negative.

Thus, our findings support the involvement of E-Selectin and HECA 452-Ag in leucocyte traffic/ endothelial cell interaction rather than in thymocyte development itself.

\section{VLA-4, VCAM-1, and FN}

VLA-4 can bind VCAM-1, or the extracellular matrix molecule FN.

Our experiments show that VLA-4 is expressed on thymocytes (at slightly higher levels in the cortex, which is consistent with flow cytometric data [Watt et al., 1992)]. However, its two ligands show totally different patterns of expression. FN forms part of the extracellular matrix, especially in the medulla - as noted in other mammals. This conserved nature of thymic FN distribution is thought to imply a functional role for extracellular matrix (Utsumi et al., 1991; Savino et al., 1993). We show that VCAM-1 is mainly expressed on cortical macrophages. This suggests that VLA-4 interacts with different ligands at different stages of thymic development. The distribution of VLA- 4 is greater than the combined distribution of its ligands. This may imply that there is control of specific interactions by modification of VLA-4 affinity. VCAM-1 may be involved in an interaction between early thymocytes and macrophages via VLA- 4 (expressed at higher levels on cortical thymocytes than medullary thymocytes), consistent with data obtained by Kyewski et al., (1982). Moreover, VCAM-1 expression is modulated by the T-cell-produced cytokine IL-4, suggesting that developing $\mathrm{T}$ cells may influence their stromal microenvironment (Ritter and Boyd, 1993). We also observed close association of VCAM$1^{+}$macrophages with cortical capillaries, although the developmental significance of this is unclear.

In this paper, we have shown that there is a differential distribution of adhesion molecules within different thymic areas, and that some adhesion molecules such as ICAM-1 are shared by different lineages, whereas others, such as ESelectin are exclusively found on thymic blood vessels. We have also shown that even where lymphocyte ligands (e.g., LFA-1, CD2, and VLA-4) have a broad distribution on thymocytes, their corresponding adhesion ligands may show more selective distributions, suggesting that different interactions/functions occur in different regions of the thymus. Overall, our results suggest that adhesion molecules are likely to be important in T-cell development, although functional experiments are needed to clarify their role.

\section{MATERIALS AND METHODS}

\section{Thymus Sections}

Thymus samples were obtained from patients (aged 0-4 years) undergoing cardiac surgery. Blocks of tissue were frozen in liquid nitrogen, and $6 \mu \mathrm{m}$ cryostat sections cut. Sections were fixed in acetone and stored at $-20^{\circ} \mathrm{C}$. Experiments were repeated on several different thymuses.

\section{Antibodies}

All antibodies were titrated before use and subsequently used at the appropriate dilution.

Primary antibodies Anti-adhesion molecule antibodies used are outlined in Table 3. "Lineagespecific" markers used included rabbit anti-keratin (Dako, High Wycombe, U.K.) to identify epithelial cells, rabbit anti-laminin (Serotec, Oxford, U.K.) to identify basement membrane associated with capsule and blood vessels, and mouse anti-CD68 (Dako) to identify macrophages. 
Secondary antibodies Peroxidase conjugated rabbit anti-mouse Ig (Dako); peroxidase conjugated swine anti-rabbit Ig (Dako); peroxidase conjugated rabbit anti-rat Ig (Dako); alkaline-phosphatase conjugated swine anti-rabbit Ig (Dako); and alkalinephosphatase conjugated rabbit anti-mouse Ig (Dako). These were all prepared and preincubated with 5\% normal human serum/TBS for 15-30 min to block binding to endogenous Ig in sections.

\section{Immunohistochemistry}

Single immunoenzyme labeling This labeling determines distribution of adhesion molecules. Sections were incubated in primary antibodies against adhesion molecules, followed by peroxidase conjugated secondary antibody. The reaction was developed using $0.1 \%$ 3,3'-diaminobenzidine tetrahydrochloride (DAB) (Sigma, Poole, U.K.) as chromogen substrate with $0.015 \% \quad \mathrm{H}_{2} \mathrm{O}_{2}$. Sections were counterstained with haematoxylin and mounted in Kaiser's gelatin-based mountant.

Double immunoenzyme labeling This labeling determines lineage of cells stained with anti-ICAM-1, -VCAM-1, -E-Selectin, and -LFA-3. Sections were incubated with these antibodies, followed by peroxidase conjugated secondary antibody, and development of reaction with $\mathrm{DAB} / \mathrm{H}_{2} \mathrm{O}_{2}$ substrate. Sections were then incubated with lineage-specific antibodies (anti-keratin, anti-laminin, and antimacrophage, CD68), followed by alkalinephosphatase conjugated secondary antibody, and the reaction developed using $0.1 \%$ fast blue BB salt (Sigma) with $0.02 \%$ napthol AS-MX phosphate (Sigma), 2\% dimethyl formamide (BDH, Poole, U.K.), and $0.2 \%$ levamisole (Sigma). (Use of immunoenzymatic techniques avoids problems with cross reactivity; antibodies that are used in the peroxidase step lose their antigenicity and binding capacity once this step is developed, and thus do not interfere with the subsequent alkaline phosphatase step.) No counterstaining was carried out. Slides were mounted as before. Sections were photographed using Kodacolor Gold ASA 200 film.

\section{ACKNOWLEDGMENTS}

The authors would like to thank Dr. D. Haskard, and Dr. W. Makgoba for generous gifts of antibodies, and the staff at Great Ormond Street Children's Hospital for collection of thymus samples.
(Received November 12, 1993)

(Accepted January 26, 1994)

\section{REFERENCES}

Albelda S.M., and Buck C.A. (1990). Integrins and other cell adhesion molecules. FASEB J. 4: 2868-2880

Arulanandam A.R., Moingeon P., Concino M.F., Recny M.A., Kato K., Koyasa S., and Reinherz L. (1993). A soluble multimetric recombinant $C D 2$ protein identifies $C D 48$ as a low affinity ligand for human CD2: Divergence of CD2 ligands during the evolution of humans and mice. J. Exp. Med. 177: 1439-1450.

Berg L.J., Pullen A.M., Fazekas de St. Groth B., Mathis D., Benoist C., and Davis M.M. (1989). Antigen/major histocompatibility complex-specific $\mathrm{T}$ cells are preferentially exported from the thymus in the presence of their MHC ligand. Cell 58: 10351046.

Berg E.L., Yoshino T., Rott L.S., Robinson, M.K., Warnock A., Kishimoto T.K., Picker L.J., and Butcher E.C. (1991). The cutaneous lymphocyte antigen is a lymphocyte homing receptor for the vascular lectin endothelial cell-leukocyte adhesion molecule 1. J. Exp. Med. 174: 1461-1466.

Boyd R.L., and Hugo P. (1991). Towards an integrated view of thymopoiesis. Immunol. Today 12: 71-79.

Boyd R.L., Tucek C.L., Godfrey D.I., Izon D.J., Wilson T.J., Davidson N.J., Bean A.G.D., Ladyman H.M., Ritter M.A., and Hugo P. (1993). The thymic microenvironment. Immunol. Today 14: $445-459$.

Carlow D.A., van Oers S.C.N., Teh S-J., and Teh H-S (1992). Deletion of antigen-specific immature thymocytes by dendritic cells requires LFA-1/ICAM interactions. J. Immunol. 148: 15951603.

de Fougerolles A.R., and Springer T.A. (1992). Intercellular Adhesion Molecule 3, a third adhesion counter receptor for Lymphocyte Function-associated Molecule 1 on resting lymphocytes. J. Exp. Med. 175: 185-190.

de Fougerolles A.R., Stacker S.A., Schwarting R., and Springer T.A. (1991). Characterization of ICAM-2 and evidence for a third counter-receptor for LFA-1. J. Exp. Med. 174: 253-267.

Denning S.M., Tuck D.T., Vollger L.W., Springer T.A., Singer K.H., and Haynes B.F. (1987). Monoclonal antibodies to CD2 and Lymphocyte Function associated Antigen-3 inhibit human thymic epithelial cell-dependent mature thymocyte activation. J. Immunol. 139: 2573-2578.

Duijvestijn A.M., Horst E., Pals S.T., Rouse B.N., Steere A.C., Picker L.J., Meijer C.J.L.M., and Butcher E.C. (1988). High endothelial differentiation in human lymphoid and inflammatory tissues defined by monoclonal antibody HECA-452. Am. J. Pathol. 130: 147-155.

Fine J.S., and Kruisbeek A.M. (1991). The role of LFA-1/ICAM-1 interactions during murine lymphocyte development. J. Immunol. 147: 2852-2859.

Jenkinson E.J., Jhittay P., Kingston R., and Owen J.J.T. (1985). Studies of the role of the thymic environment in the induction of tolerance to MHC antigens. Transplantation 39: 331-333.

Kappler J.W., Wade T., White J., Kushnir E., Blackman M., Bill J., Roehm N., and Marrack P. (1987). A T cell receptor V $\beta$ segment that imparts reactivity to a class II major histocompatibility complex product. Cell 49: 263-271.

Killeen N., Stuart S.G., Littman D.R. (1992). Development and function of $\mathrm{T}$ cells in mice with a disrupted CD2. EMBO 11: 4329-4336.

Kyewski B.A., Jenkinson E.J., Kingston R., Altevogt P., Owen M.J., and Owen J.J.T. (1989). The effects of anti-CD2 antibodies on the differentiation of mouse thymocytes. Eur. J. Immunol. 19: 951-954. 
Kyewski B.A., Rouse R.V., and Kaplan H.S. (1982). Thymocyte rosettes: Multicellular complexes of lymphocytes and bone marrow-derived stromal cells in the mouse thymus. Proc. Natl. Acad. Sci. USA 79: 5646-5650.

Lo D., and Sprent J. (1986). Identity of cells that imprint $\mathrm{H}-2$ restricted T cell specificity in the thymus. Nature 319: 672-675.

Marlin S.D., and Springer T.A. (1987). Purified Intercellular Adhesion Molecule-1 (ICAM-1) is a ligand for Lymphocyte Function-associated Antigen 1 (LFA-1). Cell 51: 813-819.

Marrack P., Lo D., Brinster R., Palmiter R., Burkly L., Flavell R.H., and Kappler J. (1988). The effect of thymus environment on T cell development and tolerance. Cell 53: 627-634.

Patel D.D., and Haynes B.F. (1993). Cell adhesion molecules involved in intrathymic T cell development. Semin. Immunol. 5: 283-292.

Pigott R. and Power C. (1993). The adhesion molecule facts book (London: Academic Press).

Picker L.J., Michie S.A., Rott L.S., and Butcher E.C. (1990). A unique phenotype of skin-associated lymphocytes in humans. Preferential expression of the HECA- 452 epitope by benign and malignant $T$ cells at cutaneous sites. Am. J. Pathol. 136: 1053-1068.

Poggi A., and Zocchi M.R. (1992). Cultured human thymocytes lacking CD2 and CD11a/CD18 antigens are functional and adhere to endothelial cells via CD56 or CDw49d molecules. Cell. Immunol. 140: 319-330.

Ritter M.A., and Crispe I.N. (1992). The thymus (Oxford: IRL Press).

Ritter M.A., and Boyd R.L. (1993). Development in the thymus: It takes two to tango. Immunol. Today 14: 462-469.

Savino W., Villa-Verde D.M.S., and Lannes-Vieira J. (1993). Extracellular matrix proteins in intrathymic T-cell migration and differentiation? Immunol. Today 14: 158-161.

Shimizu Y., Newman W., Tanaka Y., and Shaw S. (1992). Lymphocyte interactions with endothelial cells. Immunol. Today 13: 106-112.

Sprent J., von Boehmer H., and Nabholz M. (1975). Association of immunity and tolerance to host $\mathrm{H}-2$ determinants in irradiated F1 hybrid mice reconstituted with bone marrow cells from one parental strain. J. Exp. Med. 142: 321-331.

Springer, T.A. (1990). Adhesion receptors of the immune system. Nature 346: 425-434.

Staunton D.E., Dustin M.L., and Springer T.A. (1989). Functional cloning of ICAM-2, a cell adhesion ligand for LFA-1 homologous to ICAM-1. Nature 339: 61-64.

Utsumi K., Sawada M., Narumiya S., Nagamine J., Sakata T., Iwagami S., Yasumichi K., Teraoka H., Hirano H., Ogata M., Hamaoka T., and Fujiwara H. (1991). Adhesion of immature thymocytes to thymic stromal cells through fibronectin molecules and its significance for the induction of thymocyte differentiation. Proc. Natl. Acad. Sci. USA 88: 5685-5689.

Vaseux R., Hoffman P.A., Tomita J.K., Dickinson E.S., Jasman R.L., St. John T., and Gallatin W.M. (1992) Cloning and characterization of a new intracellular adhesion molecule ICAM-R. Nature 360: 485-488.

Watt S.M., Thomas J.A., Edwards A.J., Murdoch S.J., and Horton M.A. (1992). Adhesion receptors are differentially expressed on developing thymocytes and epithelium in human thymus. Exp. Hematol 20: 1101-11.

Zocchi M.R., Marelli F., and Poggi A. (1990). Simultaneous cytofluorometric analysis for the expression of cytoplasmic antigens and DNA content in $\mathrm{CD}^{-}$human thymocytes. $\mathrm{Cy}-$ tometry 11: $883-887$. 


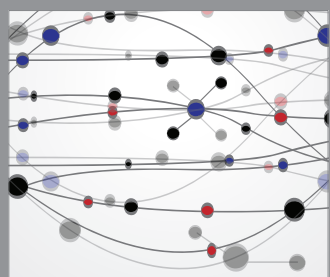

The Scientific World Journal
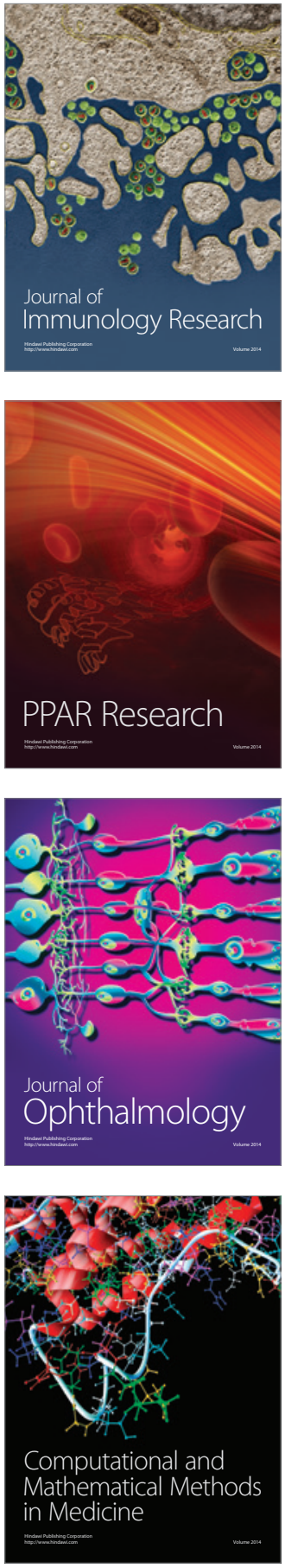

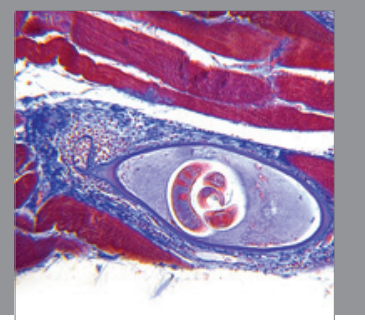

Gastroenterology

Research and Practice
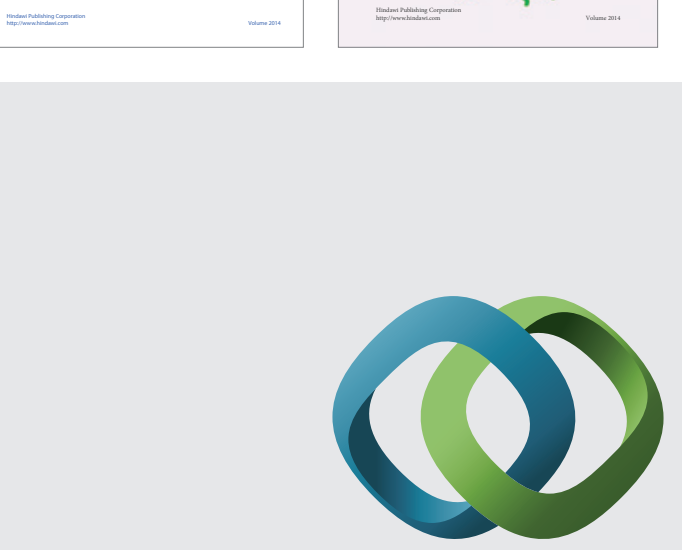

\section{Hindawi}

Submit your manuscripts at

http://www.hindawi.com
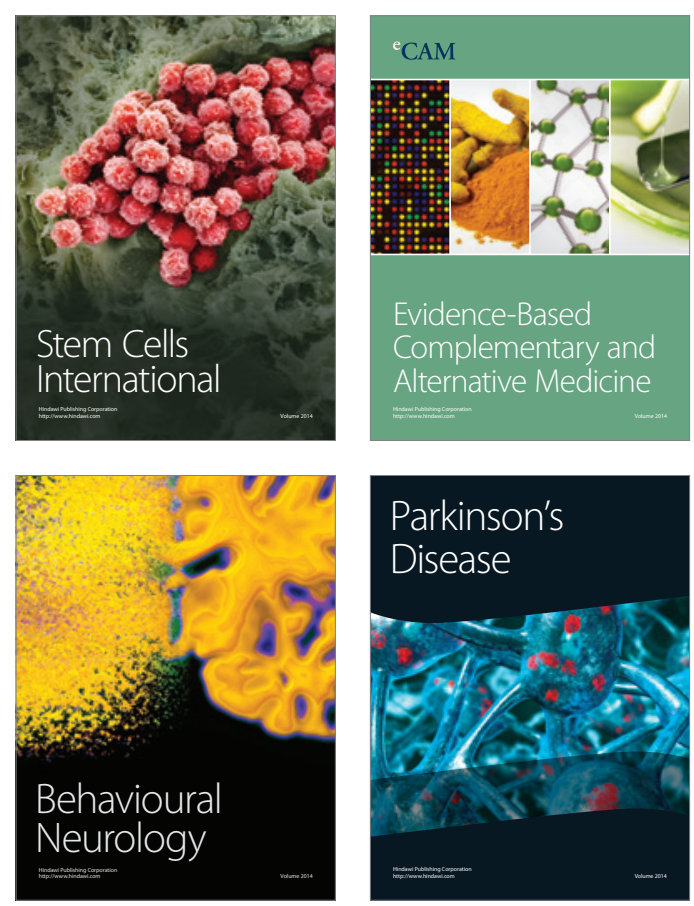

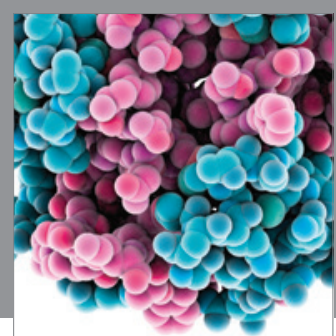

Journal of
Diabetes Research

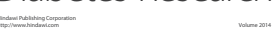

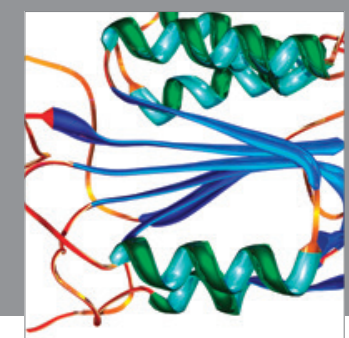

Disease Markers
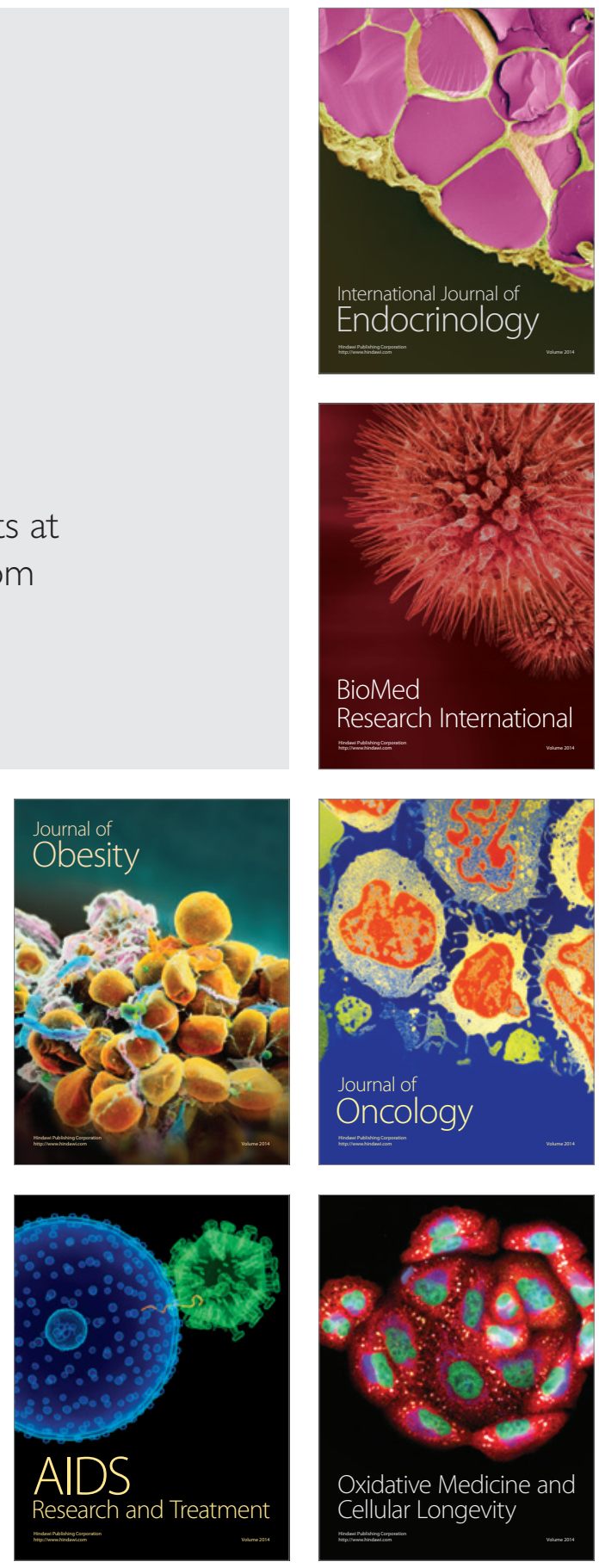